\title{
Carboxyl Methyl Cellulose@Guar Gum@ Cu0 Nanoparticle as Effective Adsorbent for the Removal of Dye From Aqueous Solution
}

\author{
Ali Hosseinian Naeini \\ Islamic Azad University \\ mohammad Reza kalaee ( $\nabla$ mohammad.kalaee@gmail.com ) \\ Islamic Azad University https://orcid.org/0000-0003-2396-7006 \\ Omid Moradi \\ Islamic Azad University \\ Ramin Khajavi \\ Islamic Azad University \\ Majid Abdouss \\ Amirkabir University of Technology
}

\section{Research Article}

Keywords: biopolymer, biocompatible, malachite green, dye Removal, copper oxide.

Posted Date: September 2nd, 2021

DOI: https://doi.org/10.21203/rs.3.rs-862550/v1

License: (9) This work is licensed under a Creative Commons Attribution 4.0 International License. Read Full License 


\section{Carboxyl methyl cellulose@Guar gum@ CuO nanoparticle as effective adsorbent for the removal of dye from aqueous solution}

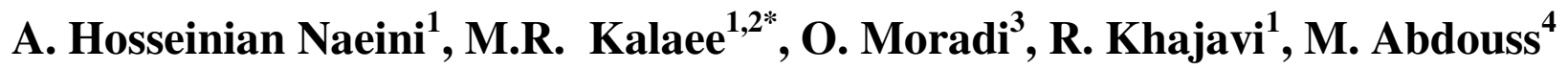

1. Department of Chemical and Polymer Engineering, South Tehran Branch, Islamic Azad University, Tehran, Iran

2. Nanotechnology Research Centre, Tehran South Branch, Islamic Azad University, Tehran 15847-43311, Iran

3. Department of Chemistry, Faculty of Science, Shahr-e-Qods Branch, Islamic Azad University, Tehran, Iran

4. Department of Chemistry, Amirkabir University of Technology, Tehran 15875-4413, Iran

*Corresponding authors:

Mohammadreza kalaee (쓰_kalaee@azad.ac.ir and mohammad.kalaee@gmail.com) 


\section{ABSTRACT}

In the present study, the study and fabrication of inorganic organic nanocomposites with Guar gam and Carboxy methyl cellulose biopolymer substrates. The synthesis nanocomposite of $\mathrm{CMC} / \mathrm{GG} / \mathrm{CuO}-3$ is biodegradable and biocompatible, and also has a significant efficiency in removing malachite green (MG) dye from aqueous solution. Properties were evaluated by XRD, FTIR, SEM, EDX and BET analysis. Important and influential parameters on the adsorption process such as adsorbent amount, initial dye concentration, $\mathrm{pH}$ and contact time on the removal efficiency of contaminants from aqueous solutions were investigated. Maximum removal efficiency and adsorption capacity were $92.4 \%$ and $18.6 \mathrm{mg} / \mathrm{g}$, respectively. In order to analyze the mechanism of experimental data, two First-order and Second-order kinetic models were used, which followed the second-order kinetics with $\mathrm{R}^{2}=1$. Also, the study of Freundlich and Langmuir isotherms showed that the isotherm model of Freundlich follows the $R^{2}=0.94$, which indicates the non-uniformity of adsorption on the adsorbent surface.

Keywords: biopolymer; biocompatible; malachite green; dye Removal; copper oxide. 


\section{Introduction}

In recent years, the industrialization and population growth of the world, due to the limited resources of fresh water, drinking water, as well as climate change due to global warming, has doubled the pressure on existing resources[1]. Many organic pollutants in water sources existing a wide range of compounds, including dyes, insecticides, petroleum products, paper, leather, plastics and rubber, detergents, oils, pharmaceutical and personal care products compounds[2]. Dyes have been widely considered and used in today's advanced industries and technologies. Colored wastewater produced in many processes in the textile industry generally contains organic compounds due to the formation of strong, toxic, carcinogenic, mutagenic and biodegradable complexes that often cause many environmental problems[3,4]. Organic dyes are chemically stable and can appear as anionic, cationic or non-ionic due to their complex aromatic structures[5]. Malachite green (MG) is a cationic dye in the form of a green crystalline powder with a metallic luster that is widely used in the textile and dyeing industries including leather, silk, cotton, wool, hair dye and paper. Disposal of organic dyes in aquatic ecosystems has adversely affected aquatic species and has become a significant source of pollution[6,7]. The presence of organic dyes in water sources due to the presence of functional groups and aromatic compounds, reduces the penetration of sunlight and affects the photosynthetic activities of aquatic animals[8]. Therefore, an effective, efficient and economical way to reduce the concentration of organic pollutants before release into the aquatic environment is needed $[9,10]$.

Therefore, separation and removal of dyes from industrial effluents has become a very important issue[11]. For this purpose, conventional physical and physicochemical methods including adsorption, biological oxidation, ultrafiltration, membrane, photocatalyst, ion exchange and chemical coagulation have been used to separate and remove colored effluents[12-14]. Among 
the mentioned methods, the absorption process is one of the most common methods due to its high efficiency, economy and simplicity of work[15]. Many researchers today seek to use adsorbents based on metal nanoparticles with biodegradable polymer compounds with high adsorption capacity and low cost, including chitin, alginate, guar gum, carboxy methyl cellulose and copper oxide and graphene oxide pointed[16-19].

Cellulose is a linear polymer with high molecular weight, natural, renewable and biodegradable with high crystallinity and strong intramolecular hydrogen bonding that is not soluble in most organic solvents[20,21]. The conversion of cellulose to its derivatives such as carboxy methyl cellulose (CMC) based on the Williamson ether reaction is a way to increase the efficiency of cellulose[22,23]. CMC was first produced from linear polysaccharide biopolymers in 1918 and is significant due to its long chain, anionic and water-soluble properties[24,25]. CMC has been considered as an alternative to synthetic polymers due to its cheapness, non-toxicity, production of transparent films, high viscosity, biodegradable and biocompatible. CMC has a variety of applications in various fields including textiles, paper industries, food, detergents, cosmetics and pharmaceuticals. CMC is synthesized from plant biomass, which in the dry state contains 40$50 \%$ cellulose, $25-40 \%$ hemicellulose and $15-35 \%$ lignin[23,26].

Guar gam (GG) is a cheap, non-toxic, biodegradable and prone to microbial degradation of natural polysaccharides that has shown the ability to effectively absorb various pollutants. GG is known as Gavar, Guwar, bean Guyan, Guaran, Glucotard, Cuarina, Cyamopsis, Cluster bean Powdered endosperm of Cyamopsis tetragonolobus seeds[27,28]. Chemically, GG is a natural non-ionic complex polysaccharide composed of the sugars galactose and mannose[29,30]. According to research, GG is stable in a wide temperature range (1-10.5) due to its non-ionic and charge less properties. GG is a substance with effective and unique properties, including film- 
forming, viscous and concentration-enhancing agent, cloding and adhesive agent, gelling and even wound healing agent. GG is also used in various applications including food, textile, paint and coating, agriculture, pharmaceutical and personal care products and biological treatment[31,32]. Metal oxides are used to improve or develop the functional properties of polymers.

Copper oxide $(\mathrm{CuO})$ nanoparticles have significant antimicrobial performance and semiconductor properties due to their specific and unique crystal structure. $\mathrm{CuO}$ nanoparticles are widely used for various applications in fields such as magnetic storage devices, catalysts, ceramics, thermal sensors and superconducting materials. Table 1 illustrating the removal efficiency of dyes with different adsorbents.

The present study investigated and fabricated an inorganic organic nanocomposite with a biopolymer substrate. In general, cellulose sources can be used as organic matter and metal particles as minerals can be used in this nanocomposite. The nanocomposite is biodegradable, biodegradable and biocompatible, and has also shown significant efficacy in removing malachite green dye. In fact, it can be said to be effective in reducing environmental pollution. Experiments were synthesized at room temperature and used as a biopolymer adsorbent to remove green malachite dye from aqueous solutions. Important and influential parameters on the adsorption process such as adsorbent amount, initial dye concentration, $\mathrm{pH}$ and contact time on the removal efficiency of contaminants from aqueous solutions were investigated. In order to analyze the mechanism of experimental data, two pseudo-first-order and pseudo-second-order kinetic models as well as Freundlich and Langmuir isotherms were used. 
Table 1

Absorption removal percentage of different dyes and adsorbent.

\begin{tabular}{cccc}
\hline Adsorbent & pollutant & Removal \% & Reference \\
\hline CMC/g-C $\mathrm{N}_{4} / \mathrm{ZnO}$ & Methyl violet & 39 & {$[33]$} \\
$\mathrm{CGOA}$ & Rhodamine B & 99.9 & {$[34]$} \\
$\mathrm{CA}$ & Methylene blue & 90 & {$[35]$} \\
$\mathrm{CGAs}$ & Congo red & 88 & {$[36]$} \\
$\mathrm{CMC} / \mathrm{GOCOOH}$ & Methylene blue & 99.9 & [37] \\
CMC/GG & Malachite green & 64 & In this Research \\
CMC/GG/CuO & Malachite green & 92.4 & In this Research
\end{tabular}

\section{Experimental}

\subsection{Materials}

Copper oxide $(\mathrm{CuO})$, Guar gum $(\mathrm{GG})$ powder and carboxy methyl cellulose (CMC) powder were purchased from *. Malachite green $(\mathrm{MG})\left(\mathrm{C}_{23} \mathrm{H}_{25} \mathrm{ClN}_{2}, \mathrm{Mw}=364.9 \mathrm{~g} / \mathrm{mol}\right)$ was procured from *. The chemical structure of Malachite green is illustrating in Fig.1. Dilute $\mathrm{HCl}$ and $\mathrm{NaOH}$ were used to adjust the $\mathrm{pH}$ of the pollutants solution. 


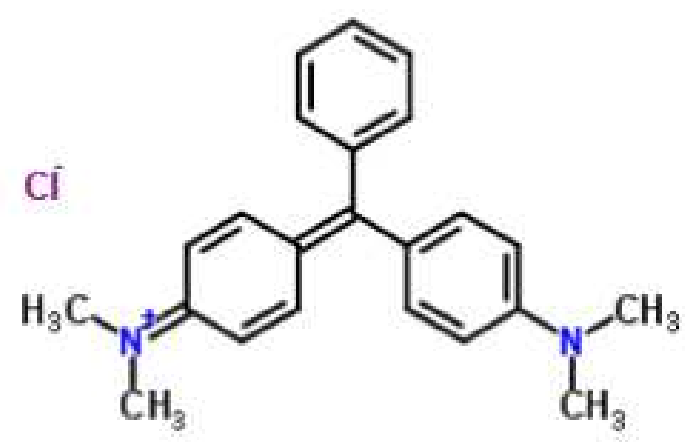

Fig.1. The chemical structure of Malachite green.

\subsection{Synthesis}

\section{Preparation of $C M C / G G$ nanocomposite}

The CMC/GG mixture was dissolved in $1 \mathrm{~g}$ of dried CMC hydrogel in $100 \mathrm{ml}$ of deionized water at room temperature under intense magnetic stirring at $700 \mathrm{rpm}$ for $1 \mathrm{~h}$. Then $1 \mathrm{~g} \mathrm{GG}$ was added to $\mathrm{CMC}$ hydrogel. The resulting mixture was subjected to intense magnetic stirring for $3 \mathrm{~h}$ for complete dissolution and the formation of a clear gel. The prepared CMC/GG hydrogel was dried at room temperature.

\section{Preparation of $\mathrm{CMC} / \mathrm{GG} / \mathrm{CuO}$ nanocomposite}

In order to synthesize the biopolymer/nanoparticle nanocomposite, $1 \mathrm{~g}$ of dried CMC hydrogel in $100 \mathrm{ml}$ of deionized water was subjected to intense magnetic stirring at $700 \mathrm{rpm}$ for $1 \mathrm{~h}$. Then 1 $\mathrm{g}$ of GG was added to $\mathrm{CMC}$ hydrogel. Then $1 \mathrm{mg} / \mathrm{ml}$ of $\mathrm{CuO}$ was gently added to the hydrogel mixture containing $\mathrm{CMC} / \mathrm{GG}$. The resulting mixture was continuously stirred vigorously with a high-speed magnetic stirrer $(700 \mathrm{rpm})$ for $3 \mathrm{~h}$ for complete and uniform dissolution and the 
formation of a clear gel. The prepared $\mathrm{CMC} / \mathrm{GG} / \mathrm{CuO}$ hydrogel was dried at room temperature. In order to optimize the adsorbent, different $\mathrm{wt} \%$ of $\mathrm{CuO}$ were prepared according to the above formulation (1, 3 and $5 \mathrm{wt} \%)$.

\subsection{Apparatus}

The Fourier Transform Infrared Spectroscopy (FT-IR) device made by Perkin Elmer Company was used to identify the properties of biopolymer nanocomposite materials synthesized in the range of 450-4000 $\mathrm{cm}^{-1}$. X-ray diffraction (XRD) to record the structure and crystalline nature of the samples using X-Ray Diffractometer with Cuka beam irradiation with a step size of .05 XRD pattern was recorded. The specific area and porosity of the adsorbents were determined using nitrogen gas adsorption method and BET isotherm model $\left(\mathrm{S}_{\mathrm{BET}}\right)$ at $77^{\circ} \mathrm{K}$ and at atmospheric pressure. From the visible-ultraviolet (UV/Vis) spectrophotometer with Lambda-25 Perkin Elmer model, the light absorption of the sample was examined. In order to study the crystal structure and morphology of the scanning electron microscope (SEM) was used using the instrument model (Zeiss EM900).

\subsection{Dye Adsorption Experiment}

The adsorption experiment of green malachite cationic dye in $100 \mathrm{ml}$ of decolorizing glass containing dye was investigated using biopolymer nanocomposite adsorbents. Dye solution with a specific initial concentration $(20 \mathrm{mg} / \mathrm{l})$ was prepared from the adsorbent and their $\mathrm{pH}$ was adjusted using solutions of hydrochloric acid and sodium hydroxide in the range of 3.5 to 6.5 . Then, by adding $0.1 \mathrm{~g}$ of adsorbent to the solution, they were stirred for $90 \mathrm{~min}$ at specified intervals by a magnetic stirrer at ambient temperature. After the agitation and centrifugation process, the absorption spectra of each solution were read by a single-beam spectrophotometer at $617 \mathrm{~nm}$ and finally the absorption rate of green malachite was calculated using Equation (2). The 
adsorption capacity $(\mathrm{mg} / \mathrm{g}) \mathrm{qt}$ for dyes at time $\mathrm{t}(\mathrm{min})$ and the adsorption capacity at equilibrium $(\mathrm{mg} / \mathrm{g})$ qe were calculated from the following equations (1), (2):

$$
R \%=\frac{\left(C_{0}-C_{t}\right)}{C_{0}} * 100
$$

$q_{e}=\frac{\left(C_{0}-C_{e}\right) V}{m}$

\section{Results and Discussion}

\subsection{Characterization}

\subsubsection{FTIR}

In order to understand the chemical nature and identify the functional groups of the materials used, FTIR analysis was performed. Fig.2 shows the FTIR spectrum of CuO, GG, CMC nanoparticles and $\mathrm{CMC} / \mathrm{GG}$ and $\mathrm{CMC} / \mathrm{GG} / \mathrm{CuO}$ biopolymer nanocomposites in the range of 450 to $4000 \mathrm{~cm}^{-1}$. For $\mathrm{CuO}$ nanoparticles, the characteristic bands observed in $3478,3390,1624$, $1118 \mathrm{~cm}^{-1}$ can be relation into symmetric stretching vibrations of $\mathrm{O}-\mathrm{H}$ bond and asymmetric $\mathrm{O}-\mathrm{H}$ bond, bending vibration and triply degenerative mode of $\mathrm{So}_{4}$, respectively. Also, the peaks observed in the vibrational state of the water molecule and the peaks of 613 and $502 \mathrm{~cm}^{-1}$ are related to the vibrational states of the $\mathrm{Cu}-\mathrm{O}$ bond. In the $\mathrm{GG}$ spectrum, band $3413 \mathrm{~cm}^{-1}$ is related to the $\mathrm{O}-\mathrm{H}$ stretching vibrations and band $2915 \mathrm{~cm}^{-1}$ is related to the $\mathrm{C}-\mathrm{H}$ stretching vibrations. While the bands observed in 1618,1418 , and $1055 \mathrm{~cm}^{-1}$ are attributed to the cyclic stretching of galactose and mannose, the $\mathrm{C}-\mathrm{H}$ bending vibration, and the $\mathrm{O}-\mathrm{H}$ bending vibration, respectively. 
Weak strips of about $707 \mathrm{~cm}^{-1}$ are due to ring tension and ring deformation of the joints. Similarly, the FTIR spectrum of CMC is shown in Fig.2. As we can see from the Fig.2, the wide absorption bands at 3417 and $2918 \mathrm{~cm}^{-1}$ correspond to the $\mathrm{O}-\mathrm{H}$ tensile band and the $\mathrm{C}-\mathrm{H}$ stretching vibration, respectively. The absorption bands appearing in 1632, 1428, 1318, and 1066 $\mathrm{cm}^{-1}$ are attributed to the stretching vibration of the carboxyl groups, $\mathrm{C}-\mathrm{H}$ deformation, $\mathrm{C}-\mathrm{O}$ stretching, and C-O-C stretching, respectively.

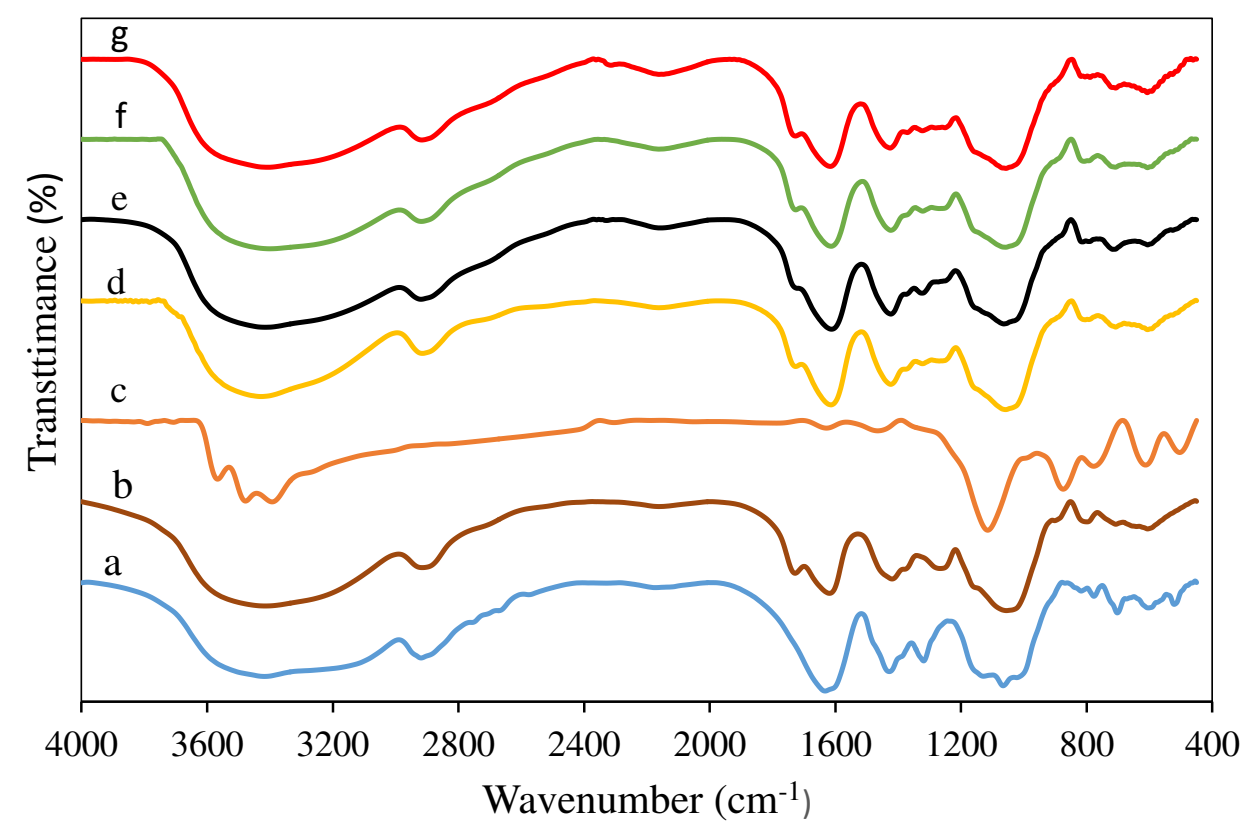

Fig.2. FTIR spectra of (a) CMC; (b) GG; (c) $\mathrm{CuO}$; (d) CMC/GG; (e) CMC/GG/CuO-5; (f) CMC/GG/CuO-3; (g) CMC/GG/CuO-1. 


\subsection{2. $X R D$}

Fig.3 shows the XRD structure of $\mathrm{CuO}$ nanoparticles and $\mathrm{GG}, \mathrm{CMC}$ and biopolymer nanocomposites of $\mathrm{CMC} / \mathrm{GG} / \mathrm{CuO}$. The results are in good agreement with the results of previous sources. The XRD pattern of the samples with an angle of $2 \Theta$ in the range of $5^{\circ}-75^{\circ}$ is shown in Fig.3. The XRD pattern confirms that $\mathrm{CuO}$ nanoparticles have a monoclinic and crystalline structure with characteristic peaks of $33.5^{\circ}, 35.65^{\circ}, 38.9^{\circ}, 48.83^{\circ}, 53.61^{\circ}$ and $61.75^{\circ}$. The characteristic peak of GG at $20.06^{\circ}$ indicates that it has extensive polymer networks. The XRD pattern of CMC with characteristic peaks of $19.15^{\circ}, 27.55^{\circ}, 31.75^{\circ}, 45.65^{\circ}$ and $56.71^{\circ}$ with an angle of $2 \Theta$ shows an amorphous and crystalline structure. The XRD pattern shows that increasing the weight percentage of $\mathrm{CuO}-\mathrm{NPs}$ in the $\mathrm{CMC} / \mathrm{GG} / \mathrm{CuO}$ matrix reduces the peak intensity. Also, $\mathrm{CMC} / \mathrm{GG} / \mathrm{CuO}$ biopolymer nanocomposite has a monoclinic structure.

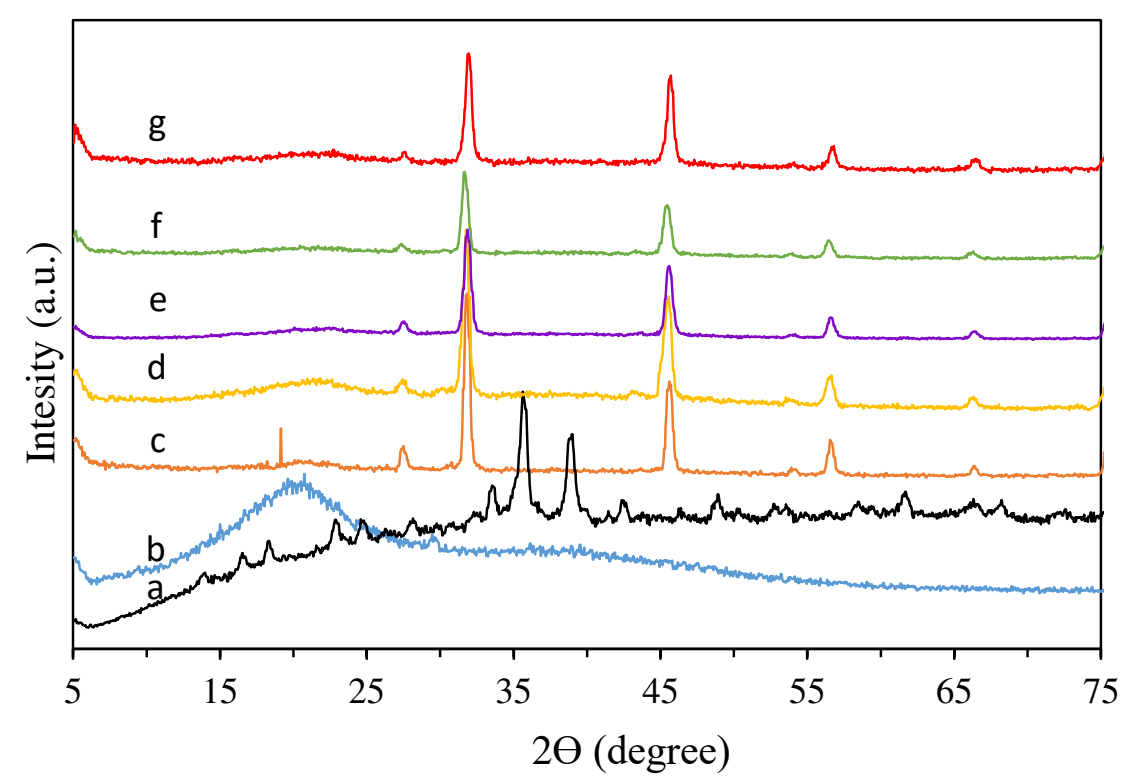

Fig.3. XRD pattern of (a) $\mathrm{CuO}$; (b) GG; (c) CMC; (d) CMC/GG ; (e) CMC/GG/CuO-5; (e) CMC/GG/CuO-3; (f) CMC/GG/CuO-1. 


\subsubsection{SEM}

The surface morphology of the samples used was determined using scanning microscope images. SEM images are shown in Fig.4. As can be seen from Fig.4-a, $\mathrm{CuO}$ nanoparticles have a monodisperse morphology with a distinct crystalline structure and are almost uniform in that the diameter of $\mathrm{CuO}$ nanoparticles varies from 30 to $50 \mathrm{~nm}[38,39]$. The SEM image of the CMC biopolymer shows an irregular shape and an uneven surface (Fig.4-b)[40,41]. GG image has cavities, irregular, layered and heterogeneous appearance (Fig.4-c)[42]. CMC/GG/CuO-3 nanocomposite is porous and layered according to Fig.4-d. $\mathrm{CuO}$ nanoparticles are also clearly visible on the CMC/GG biopolymer composite, indicating that the $\mathrm{CuO}$ has been successfully loaded on the CMC/GG composite. 


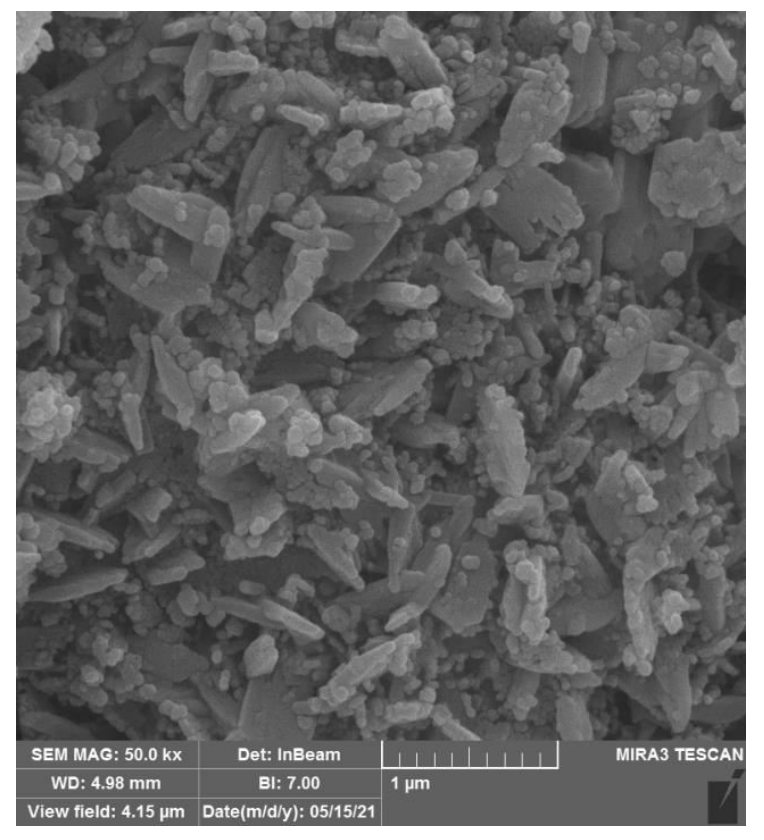

(a)

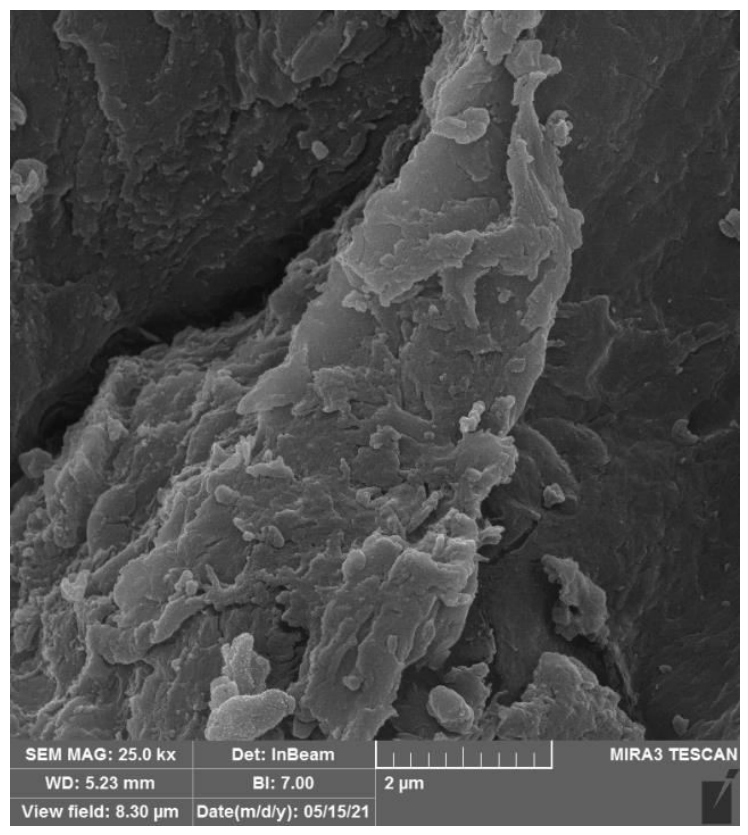

(c)

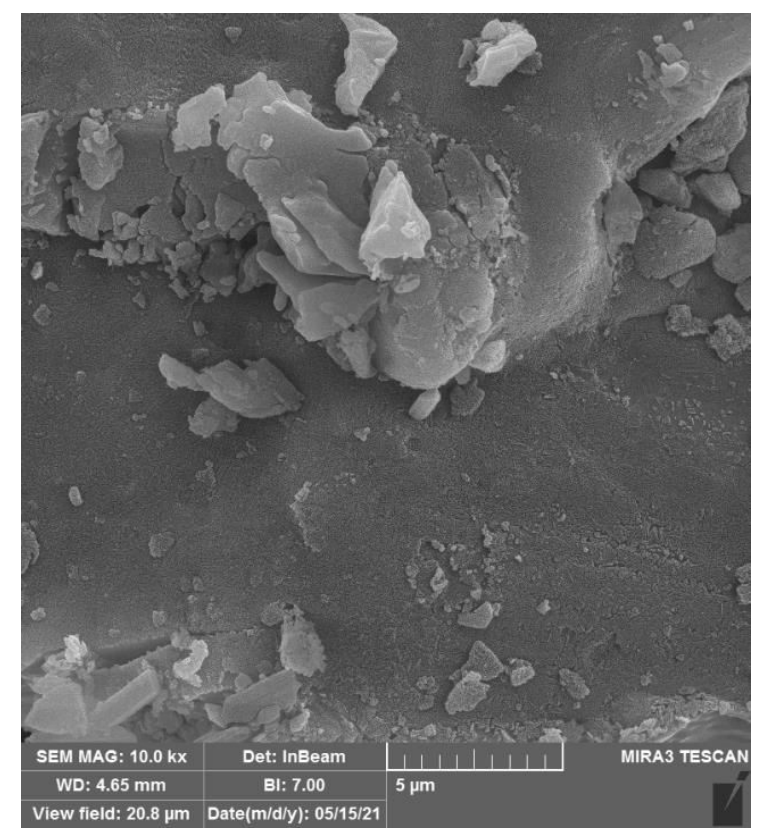

(b)

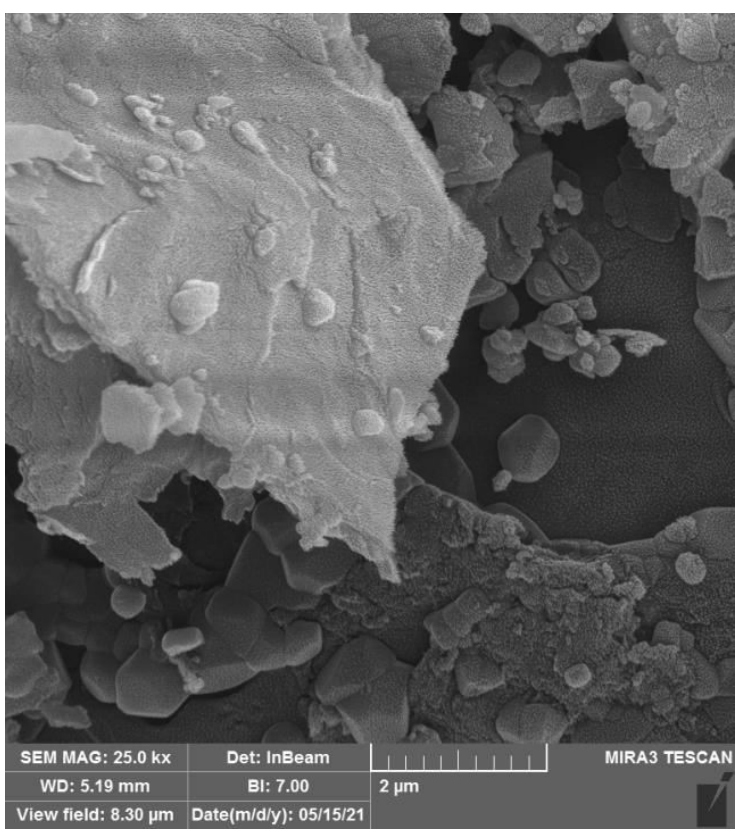

(d)

Fig.4. SEM images: (a) $\mathrm{CuO}$; (b) $\mathrm{CMC}$; (c) $\mathrm{GG}$; (d) $\mathrm{CMC} / \mathrm{GG} / \mathrm{CuO}-3$. 


\subsection{4. $E D X$}

EDX analysis was performed to evaluate the structural analysis and chemical properties of the samples used. Table 2 shows the results obtained. According to Table 3, the main chemical elements, namely $\mathrm{C}, \mathrm{O}$ and $\mathrm{Cu}$, are clearly visible and no impurities from the composition of other elements are visible.

Table 2

EDX analysis of $\mathrm{CuO}, \mathrm{CMC}, \mathrm{GG}$, and $\mathrm{CMC} / \mathrm{GG} / \mathrm{CuO}-3$.

\begin{tabular}{c|c|c|c}
\hline Sample & Element & wt \% & Atomic \% \\
\hline $\mathrm{CuO}$ & $\mathrm{C}$ & 7.95 & 18.91 \\
& $\mathrm{O}$ & 29.74 & 53.08 \\
\hline $\mathrm{CMC}$ & $\mathrm{Cu}$ & 62.31 & 28.01 \\
\hline $\mathrm{GG}$ & $\mathrm{C}$ & 39.15 & 46.15 \\
& $\mathrm{O}$ & 60.85 & 53.85 \\
\hline $\mathrm{CMC} / \mathrm{GG} / \mathrm{CuO}-3$ & $\mathrm{C}$ & 39.87 & 46.90 \\
& $\mathrm{C}$ & 60.13 & 53.10 \\
\hline & $\mathrm{O}$ & 28.99 & 37.85 \\
& $\mathrm{Cu}$ & 60.85 & 59.65 \\
\hline
\end{tabular}




\subsubsection{BET}

BET theory is based on the extended Langmuir theory and is based on the multilayer adsorption of gas molecules on the solid surface due to the non-uniformity of the adsorbent surface and the interaction of gas molecules with each other. The porosity and specific surface area of the samples were measured by nitrogen adsorption and desorption isotherms at $77^{\circ} \mathrm{K}$. Table 3 lists the specific BET level for all samples. According to Fig.5, the behavior of the samples reversibly shows the isothermal behavior of the III type. The hysteresis ring expresses the structure of the mesopores. According to the results presented in Table 3, CMC/GG/CuO-1 composite has a larger surface area and pore size than other composites. This increase can be attributed to the nonblockage of pores and cavities by $\mathrm{CuO}$ functional groups.

Table 3

BET analysis of synthesized samples.

\begin{tabular}{lccc}
\hline Sample & $\begin{array}{c}\text { BET surface } \\
\text { area }\left(\mathrm{m}^{2} / \mathrm{g}\right)\end{array}$ & $\begin{array}{c}\text { Total pore } \\
\text { volume }\left(\mathrm{cm}^{3} / \mathrm{g}\right)\end{array}$ & $\begin{array}{c}\text { Average pore diameter } \\
(\mathrm{nm})\end{array}$ \\
\hline $\mathrm{CuO}$ & 31.55 & 0.054 & 6.8 \\
\hline $\mathrm{GG}$ & 9.99 & 0.012 & 4.82 \\
\hline $\mathrm{CMC}$ & 0.15 & 0.016 & 434.59 \\
\hline CMC/GG & & & 1.61 \\
\hline CMC/GG/CuO_1 & 38.03 & 0.015 & 4.34 \\
\hline
\end{tabular}




\begin{tabular}{llll}
\hline CMC/GG/CuO_3 & 22.17 & 0.017 & 3.54 \\
\hline CMC/GG/CuO_5 & 0.19 & 0.02 & 454.32 \\
\hline
\end{tabular}

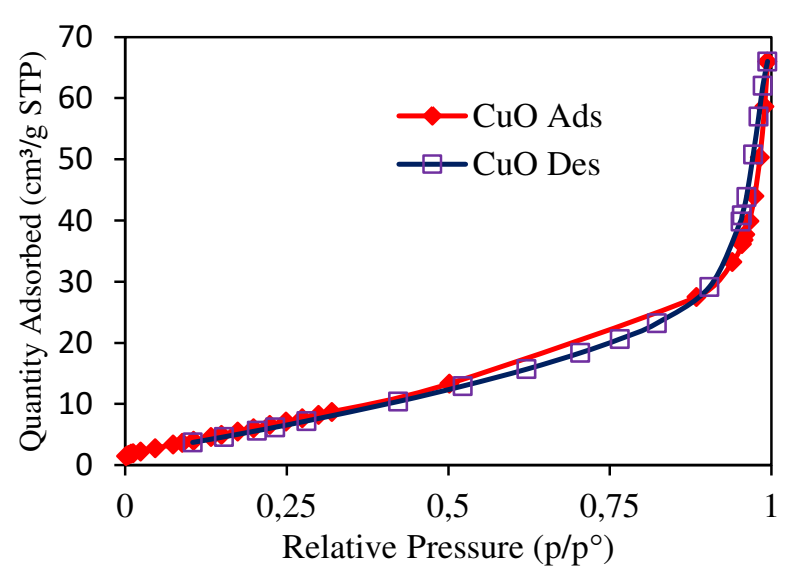

(a)

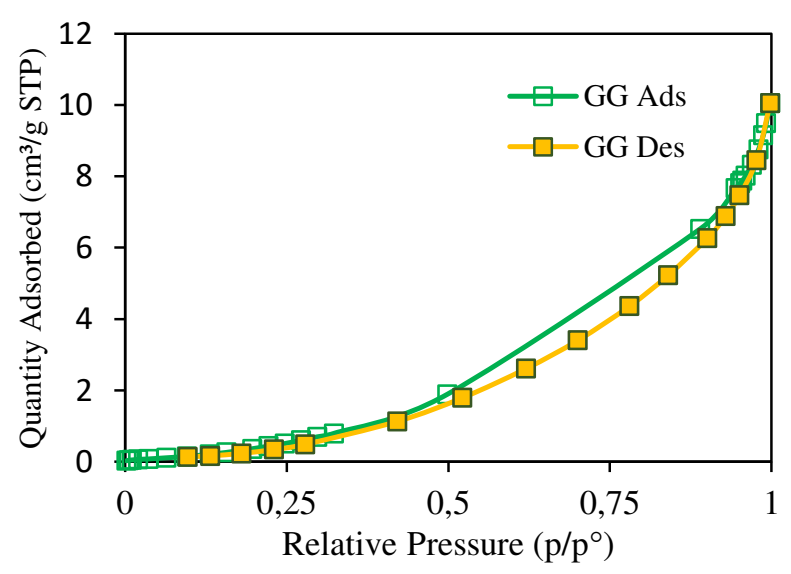

(c)

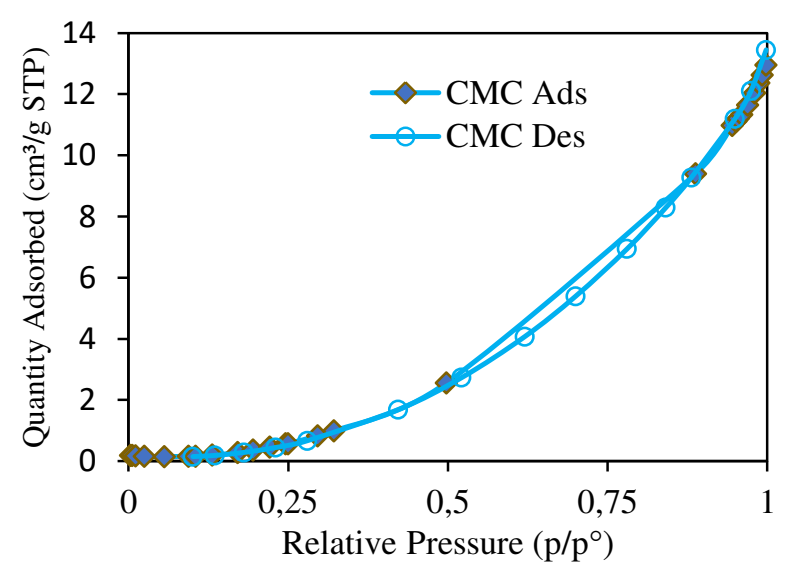

(b)

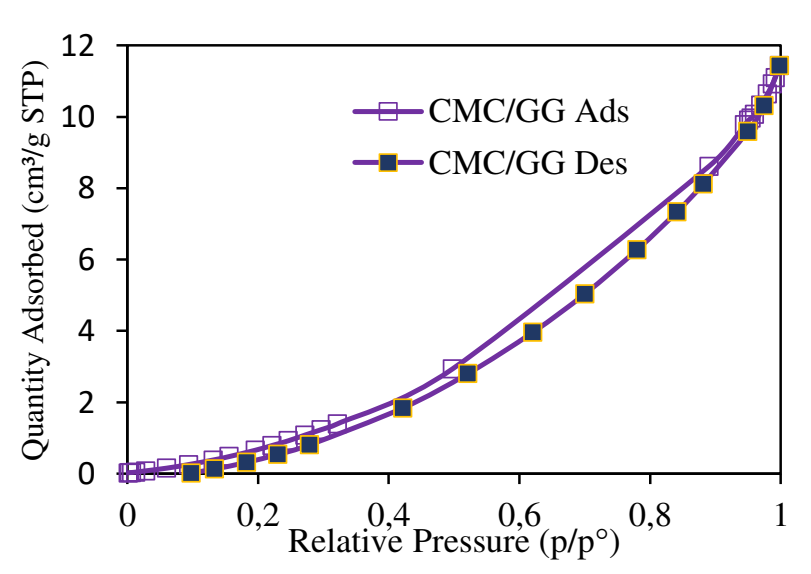

(d) 


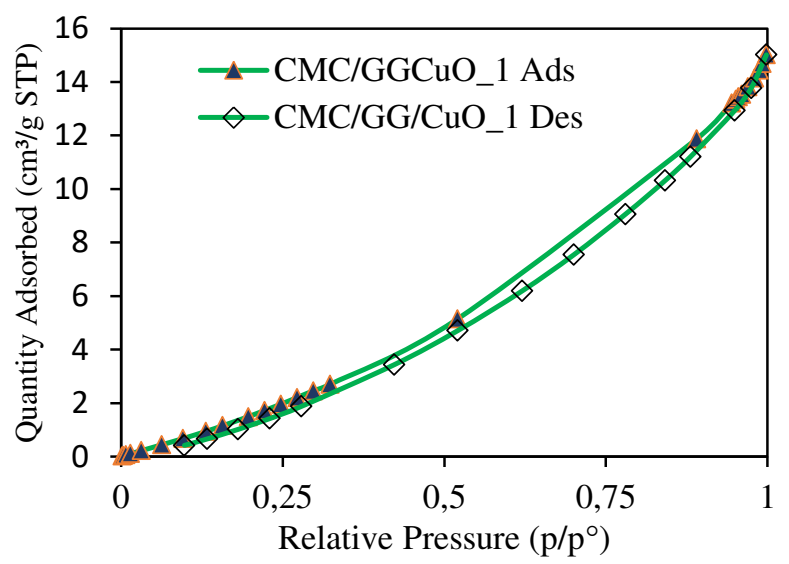

(e)

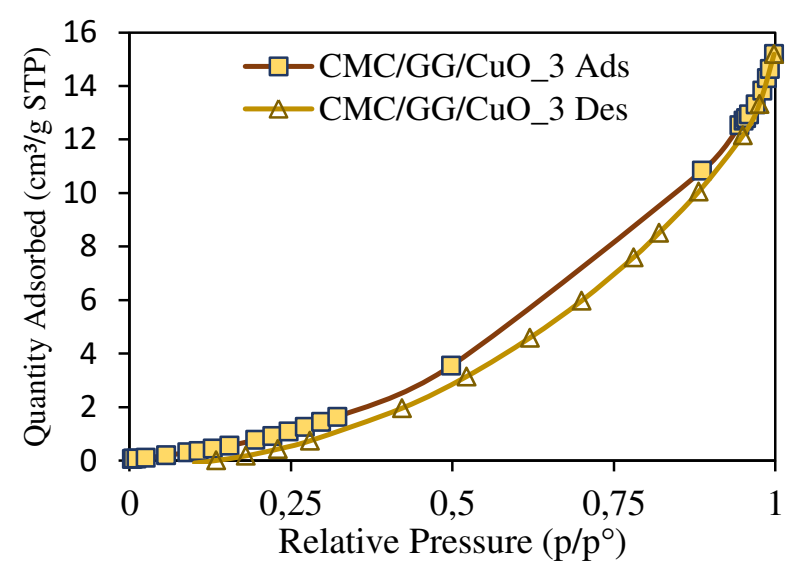

(f)

Fig.5. Nitrogen adsorption-desorption isotherm of material.

\subsection{Pollutant removal}

\subsubsection{Effect Ratio}

To optimize the adsorbent, the effect of different ratios of $\mathrm{CuO}(1,3,5 \mathrm{mg} / \mathrm{ml})$ on the biopolymer CMC/GG was loaded at room temperature (Fig.6). According to the results shown in Fig.6, by changing the load of $\mathrm{CuO}$, the amount of adsorption capacity changes significantly. As can be seen, the amount of loading agent $1 \mathrm{mg} / \mathrm{ml}$ has a higher adsorption capacity (18.6 $\mathrm{mg} / \mathrm{g}$ ) than the other two values. Increasing the load of $\mathrm{CuO}$ causes blockage of pores and pores of biopolymer nanocomposites. Therefore, the optimal dose of $\mathrm{CuO}$ on $\mathrm{CMC} / \mathrm{GG}$ biopolymers was selected to be $1 \mathrm{mg} / \mathrm{ml}$. 


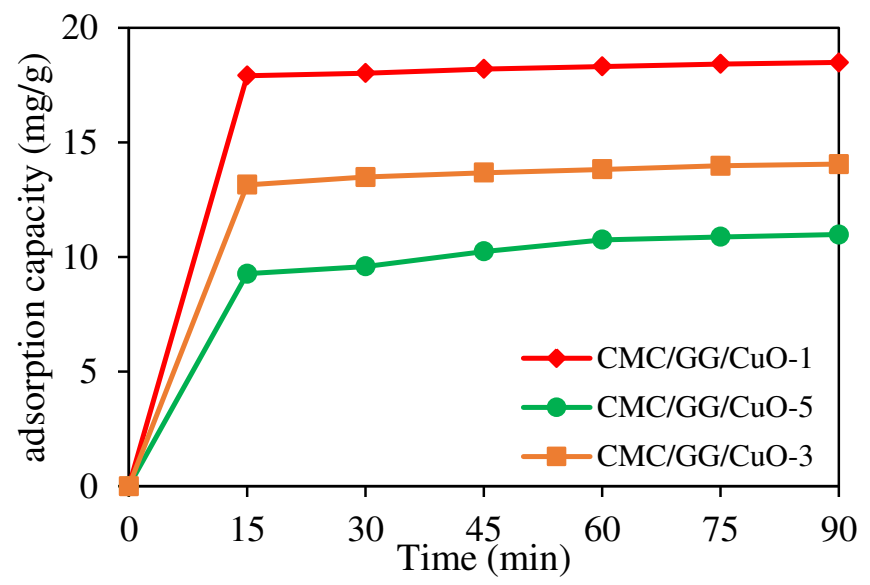

Fig.6. Effect of different ratios $(1,3$ and $5 \mathrm{mg} / \mathrm{ml})$

$\mathrm{CMC} / \mathrm{GG} / \mathrm{CuO}$ on the adsorption capacity.

\subsubsection{Initial concentration pollutant}

The effect of initial dye concentration on the removal of MG dye with synthesized adsorbents was studied. The amount of $0.1 \mathrm{~g}$ of adsorbent was determined in $100 \mathrm{ml}$ of dye solution at different concentrations (20, 30, 40 and $50 \mathrm{mg} / \mathrm{l}$ ) and with optimal pH adjustment (6.5). Approximately $89 \%$ dye removal occurs with an initial concentration of $20 \mathrm{mg} / \mathrm{L}$ in the first 15 min of the process. According to Fig.7, with increasing the initial concentration of dye solution, the percentage of dye removal decreased[43]. The final amount of removal efficiency $92.4 \%$ percentage and the amount of adsorption capacity $18.5 \mathrm{mg} / \mathrm{g}$ were obtained. By increasing the concentration of dyes, repulsion is created between the dyes molecules and they are prevented from being absorbed by the adsorbent $[42,44]$. 


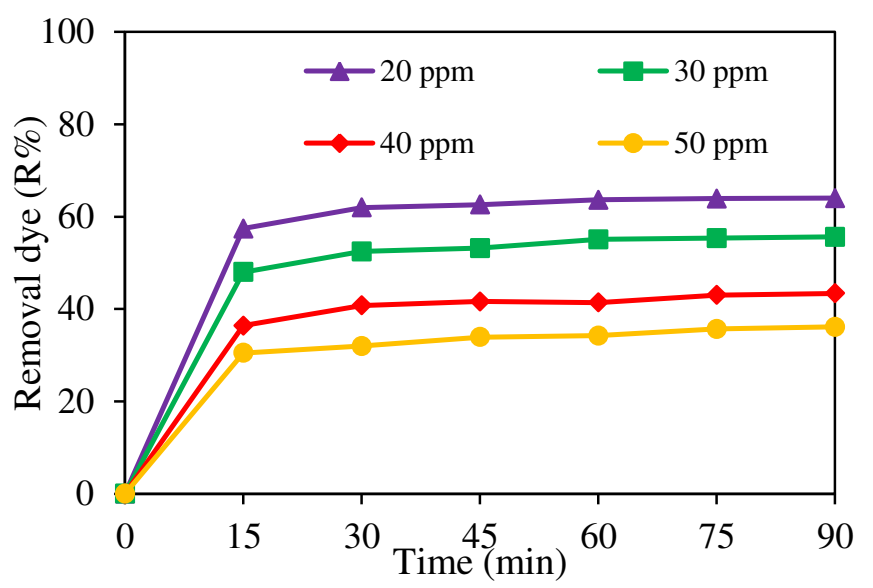

(a)

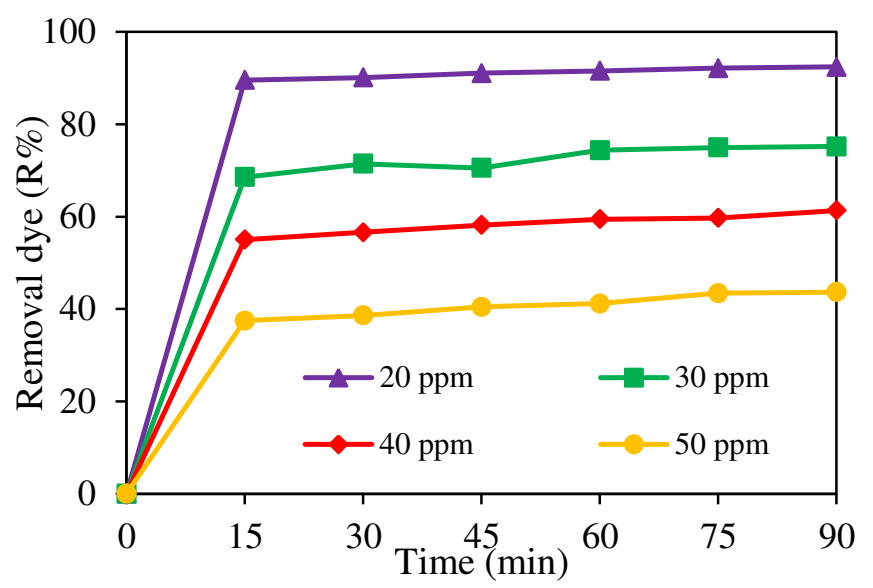

(b)

Fig.7. Effect of initial concentration pollutants (20, 30, 40 and $50 \mathrm{mg} / \mathrm{l}$ ) (a) CMC/GG; (b) CMC/GG/CuO on dye MG.

\subsubsection{Effect $p H$}

The $\mathrm{pH}$ of the solution is one of the most important factors in the adsorption process that can change the surface charge of the adsorbents as well as the separation of the functional groups present in the adsorbent adsorption active sites. In order to investigate the effect of $\mathrm{pH}$ on the adsorption of MG dye with biopolymer adsorbents, a dye solution with an initial concentration of $20 \mathrm{mg} / \mathrm{l}$ and an optimal adsorbent dose of $0.1 \mathrm{~g}$ was prepared and their $\mathrm{pH}$ was diluted with hydrochloric acid and sodium hydroxide in different $\mathrm{pH}$ ranges to 3.5 to 6.5 (Fig.8). Since MG dyes change structure at $\mathrm{pH}$ above 7 , it was not tested above 6.5. The results of this study are shown in Fig.8. The max removal efficiency (92.4\%) of $\mathrm{MG}$ was observed at $\mathrm{pH}=6.5$. The $\mathrm{MG}$ dye is positively charged when dissolved in water. In other words, by lowering the $\mathrm{pH}$ (in an acidic environment), the number of positively charged sites increases and the removal efficiency decreases. As can be seen, when the $\mathrm{pH}$ of the solution is increased from 3.5 to 6.5 , the adsorbent 
surface becomes negatively charged and therefore increases the removal efficiency of MG due to the increased electrostatic attraction between the positively charged cationic dye and the negatively charged biopolymer adsorbent $[7,19,45]$.

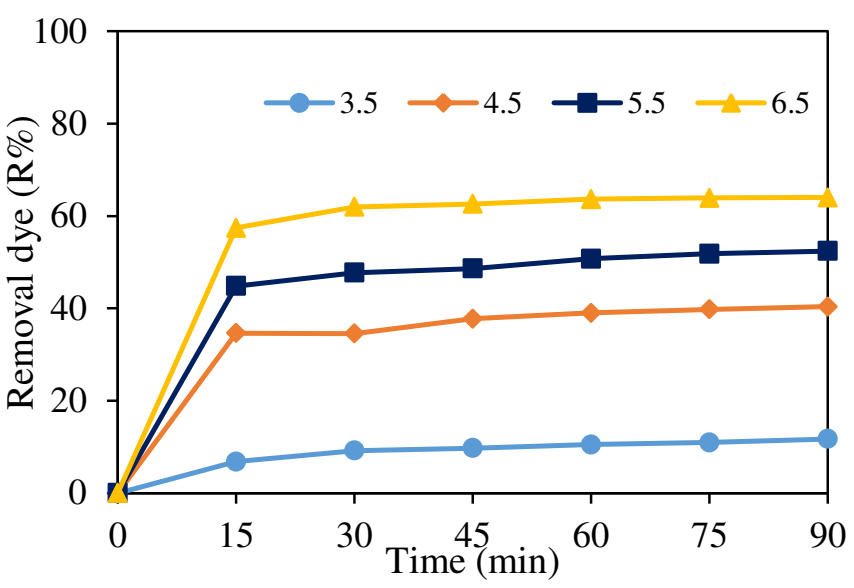

(a)

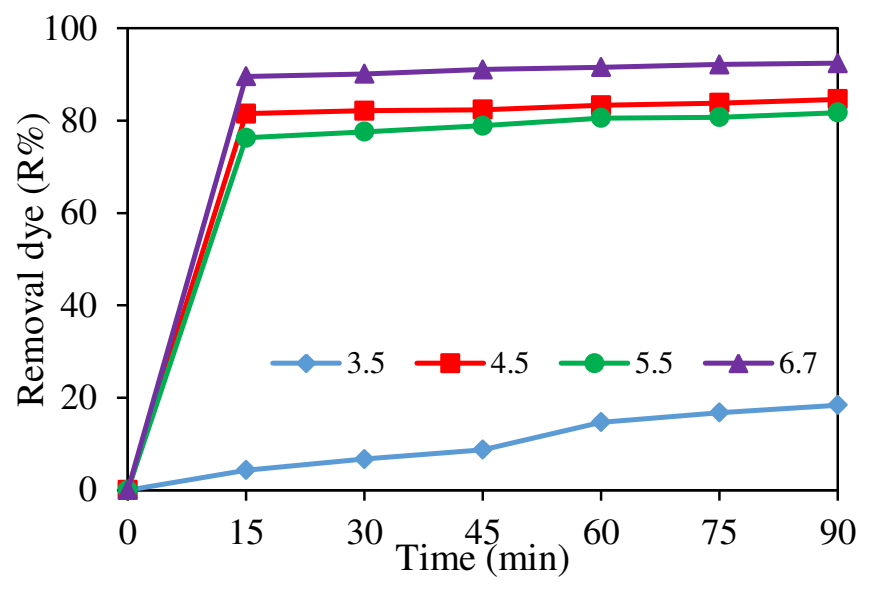

(b)

Fig.8. Effect of $\mathrm{pH}(3.5,4.5,5.5$ and, 6.5) (a) $\mathrm{CMC} / \mathrm{GG}$; (b) $\mathrm{CMC} / \mathrm{GG} / \mathrm{CuO}$ on dye MG.

\subsubsection{Adsorption contact time}

Effect of contact time on MG dye adsorption capacity with CMC/GG and CMC/GG/CuO biopolymer adsorbents in the range of $15-90 \mathrm{~min}$ and by keeping other parameters constant (initial dye concentration $20 \mathrm{mg} / \mathrm{l}$ ), the amount of adsorbent $0.1 \mathrm{~g}$ and $\mathrm{pH}=6.5$ were evaluated at room temperature. The results of this study are shown in Fig.9. The results showed that the amount of MG dye adsorption capacity for adsorbent CMC/GG $(12.8 \mathrm{mg} / \mathrm{g})$ and $\mathrm{CMC} / \mathrm{GG} / \mathrm{CuO}$ $(18.4 \mathrm{mg} / \mathrm{g})$ increases with increasing contact time. Dye ions have more time to bind to active adsorption sites on the adsorbent surface. For this reason, the absorption capacity initially increases rapidly and then slows down. Further slowing of the adsorption rate is probably due to the gradual saturation of the adsorption and adsorption active sites by the dye molecules, so 
increasing the contact time will not affect the adsorption capacity. Therefore, the final contact time for all experiments was $90 \min [46-48]$.

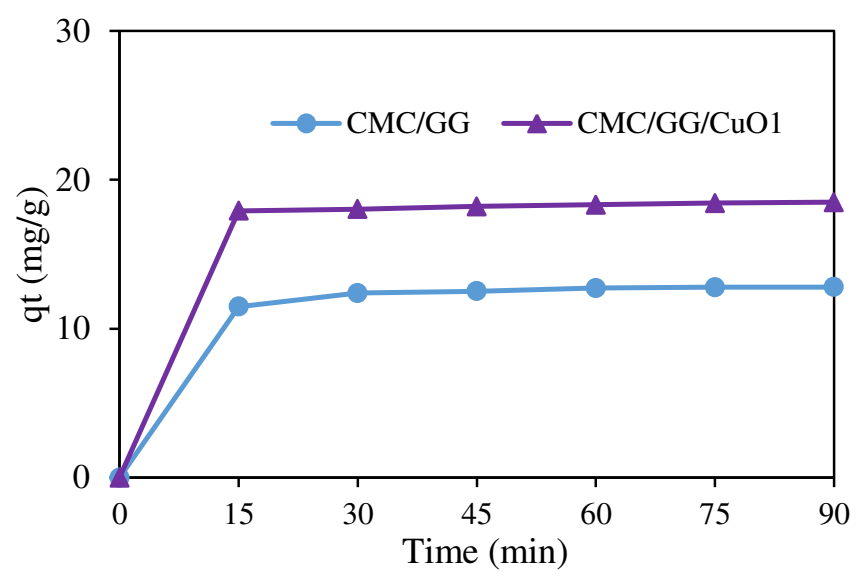

Fig.9. Effect of contact time (15-90 min) (a) CMC/GG;

(b) $\mathrm{CMC} / \mathrm{GG} / \mathrm{CuO}$ on dye $\mathrm{MG}$.

\subsubsection{Effect Dosage}

Adsorption of cationic dyes on $\mathrm{CMC} / \mathrm{GG}$ and $\mathrm{CMC} / \mathrm{GG} / \mathrm{CuO}$ biopolymer nanocomposite adsorbents by changing the amount of adsorbent from $0.05 \mathrm{~g}$ to $0.1 \mathrm{~g}$ at constant room temperature, initial concentration $20 \mathrm{mg} / \mathrm{l}$ and $\mathrm{pH} 6.5$ were studied. According to the results observed in Fig.10, by increasing the amount of adsorbent from 0.05 to $0.1 \mathrm{~g}$, the amount of adsorption increases significantly, this increases the desired level of adsorbent and the availability of more active adsorption sites for adsorption. Dye molecules are attributed. However, by changing the amount of adsorbent from $0.05-0.1 \mathrm{~g}$, the amount of dye removal increases significantly (from 67.6 to $92.4 \%$ ). Therefore, $0.1 \mathrm{~g}$ was selected as the optimal absorbent dose for all experiments[49,50]. 


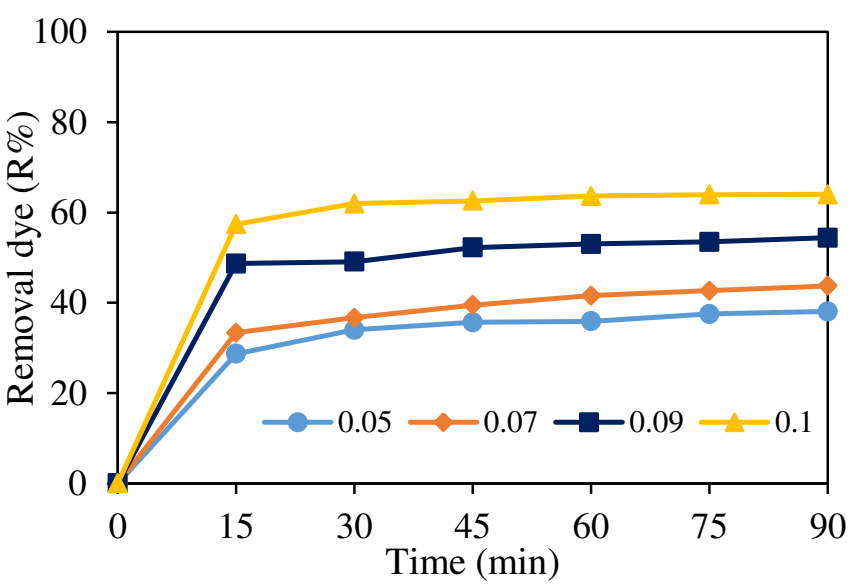

(a)

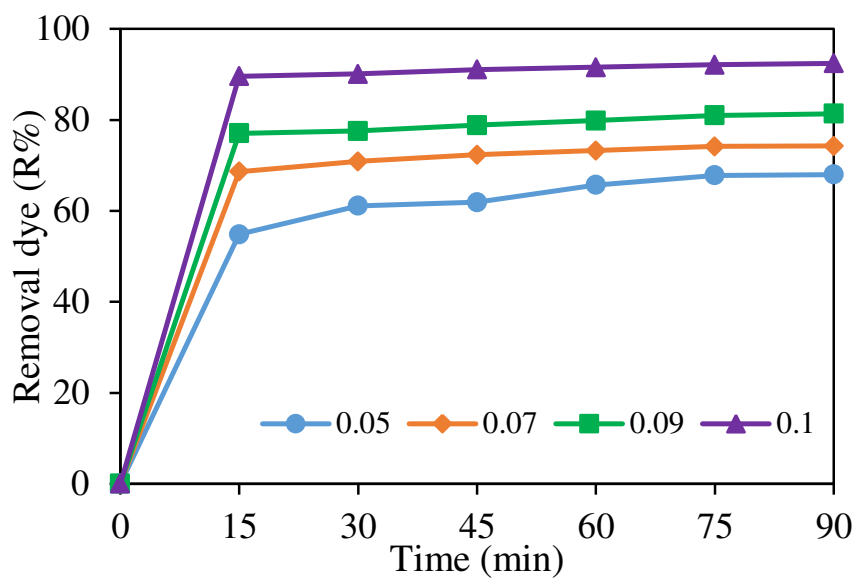

(b)

Fig.10. Effect of dosage (5, 7, 9 and, $10 \mathrm{mg}$ ) (a) CMC/GG; (b) CMC/GG/CuO on dye MG.

\subsubsection{Adsorption Isotherms}

Isotherm expresses the relationship between the concentration of adsorbent in solution and the amount of adsorbent on the adsorbent surface physically or chemically at a constant temperature. In this way, the adsorption capacity of the adsorbent in equilibrium is determined with the help of special constants that indicate the surface properties as well as the adsorbent tendency to adsorb the contaminant. In this study, Langmuir and Freundlich isotherms were used. Fig.11 shows the results of the Langmuir and Freundlich isotherm study in the adsorption process with biopolymer adsorbents $\mathrm{CMC} / \mathrm{GG}$ and $\mathrm{CMC} / \mathrm{GG} / \mathrm{CuO}$. Table 4 presents the results of data analysis on Langmuir and Freundlich isotherm models with the mentioned adsorbents. The value obtained for the $\mathrm{R}^{2}$ of each isotherm with the adsorbents 0.7594 and 0.9913 indicates that both adsorbents follow the Langmuir isotherm.

The linear equation for the Langmuir and Freundlich isotherms is given in Equation (3) and (4) $[51-54]$ : 
$C_{e} / q_{e}=1 / K_{l} \cdot q_{l}+C_{e} / q_{l}$

$\operatorname{loq} q e=\operatorname{loq} K f+\frac{1}{n} \operatorname{loq} C e$

In these relations, $\mathrm{C}_{\mathrm{e}}$ is the concentration of dye in equilibrium $(\mathrm{L} / \mathrm{mg})$ and $\mathrm{q}_{\mathrm{e}}$ is the amount of adsorbed material per absorbent body in equilibrium ( $\mathrm{mg} / \mathrm{g}$ ). The $\mathrm{q}_{\mathrm{l}}$ and $\mathrm{K}_{\mathrm{f}}$ constants show the adsorption capacity of the monolayer. Also, the dimensionless constants $\mathrm{n}$ and $\mathrm{Kf}$ indicate the adsorption capacity and intensity, respectively.

Table 4

Isotherm parameters for $\mathrm{MG}$ dye adsorption on $\mathrm{CMC} / \mathrm{GG}$ and $\mathrm{CMC} / \mathrm{GG} / \mathrm{CuO}$ nanocomposite.

\begin{tabular}{|c|c|c|c|}
\hline \multirow[t]{2}{*}{ Isotherm } & \multirow[t]{2}{*}{ parameter } & \multicolumn{2}{|c|}{ Adsorbents } \\
\hline & & $\mathrm{CMC} / \mathrm{GG}$ & $\mathrm{CMC} / \mathrm{GG} / \mathrm{CuO}$ \\
\hline Langmuir & $\mathrm{q}_{\mathrm{L}}$ & 18.41 & 12.69 \\
\hline \multirow[t]{2}{*}{$\mathrm{C}_{\mathrm{e}} / \mathrm{q}_{\mathrm{e}}=1 / \mathrm{K}_{\mathrm{L}} \mathrm{q}_{\mathrm{L}}+\mathrm{C}_{\mathrm{e}} / \mathrm{q}_{\mathrm{L}}$} & $\mathrm{K}_{\mathrm{L}}$ & 0.25 & 1.61 \\
\hline & $\mathrm{R}^{2}$ & 0.7598 & 0.9913 \\
\hline Freundlich & $\mathrm{K}_{\mathrm{F}}$ & 7.60 & 20.40 \\
\hline \multirow[t]{2}{*}{$\log q_{e}=\log K_{f}+1 / n \log C_{e}$} & $n$ & 4.19 & 4.98 \\
\hline & $\mathrm{R}^{2}$ & 0.3122 & 0.9437 \\
\hline
\end{tabular}




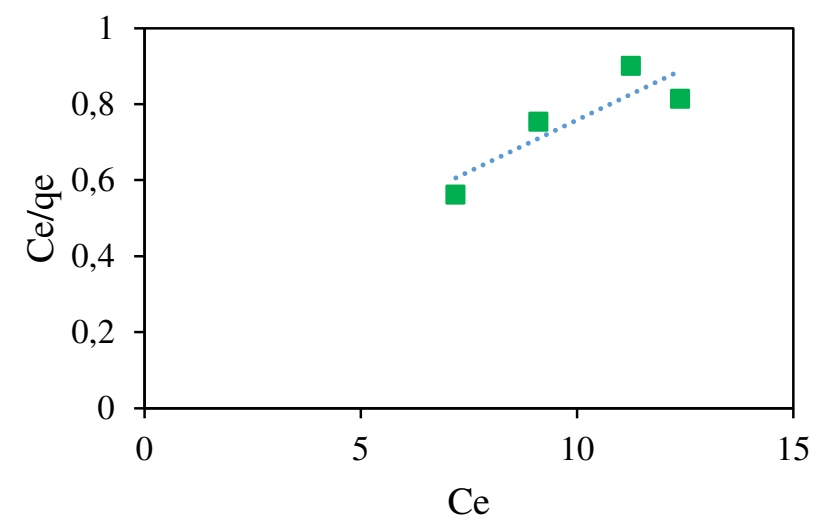

(a)

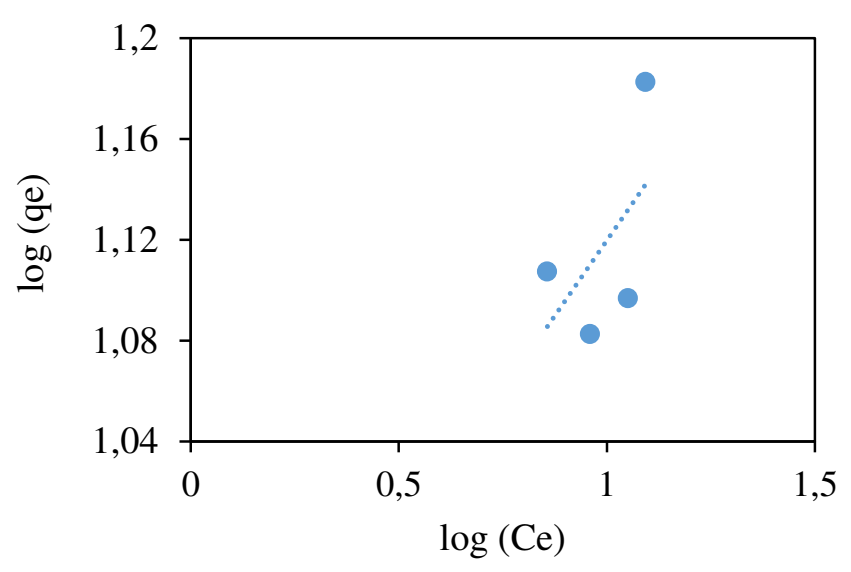

(c)

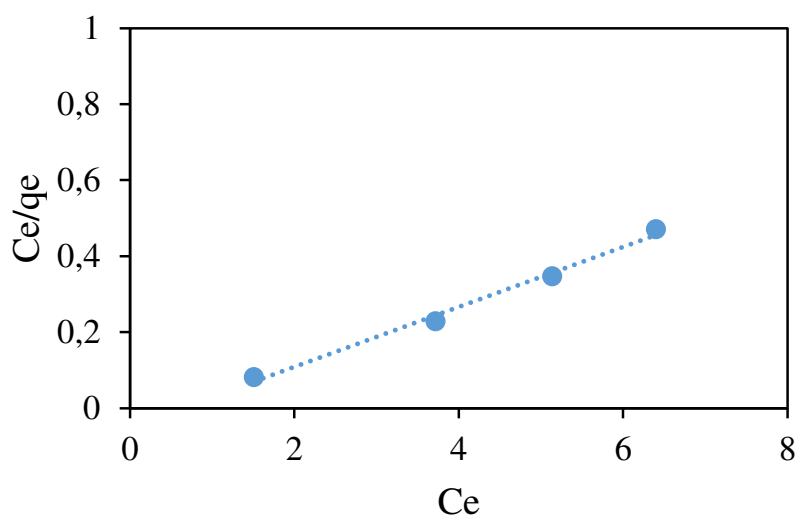

(b)

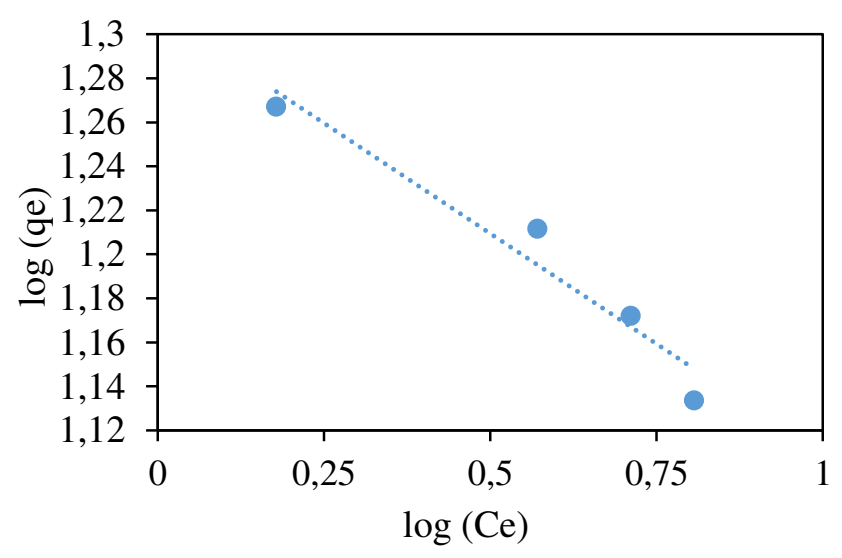

(d)

Fig.11. The Langmuir isotherm (a) $\mathrm{CMC} / \mathrm{GG}$; (b) $\mathrm{CMC} / \mathrm{GG} / \mathrm{CuO}$ and the Freundlich isotherm nanocomposites (c) $\mathrm{CMC} / \mathrm{GG}$; (d) $\mathrm{CMC} / \mathrm{GG} / \mathrm{CuO}$ on dye $\mathrm{MG}$.

\subsubsection{Adsorption kinetic}

The adsorption kinetics investigates the relationship between the reaction rate and the interactions between the adsorbent and the adsorbent. Using equilibrium data of adsorption, the kinetics of reaction and its degree of agreement with quasi-first-order quasi-equations were investigated. Fig.13 shows the results of a pseudo-first-order and second-order kinetic study in 
the adsorption process of biopolymer adsorbents $\mathrm{CMC} / \mathrm{GG}$ and $\mathrm{CMC} / \mathrm{GG} / \mathrm{CuO}$. Table 5 presents the results of data fitting on first-order and second-order kinetic models of the mentioned adsorbents. According to the values of $\mathrm{R}^{2}$ (correlation coefficient) obtained for both kinetic models, with biopolymer adsorbents $\mathrm{CMC} / \mathrm{GG}$ and $\mathrm{CMC} / \mathrm{GG} / \mathrm{CuO}$ greater $\mathrm{R}^{2}\left(\mathrm{R}^{2}=1\right)$ value in the second-order model compared to the first-order model, in the presence of both adsorbents it can be stated that the process under study Follows the second-order model[53,55-57].

The linear shape of the models is as follows (5) and (6):

First order kinetics (5):

$\log (\mathrm{qe}-\mathrm{qt})=\log q e-(K 1 / 2.303) \cdot t$

Second order kinetics (6):

$\frac{\mathrm{t}}{\mathrm{q}_{\mathrm{t}}}=1 / \mathrm{K}_{2} \mathrm{qe}^{2}+\mathrm{t} / \mathrm{qe}$

Where $\mathrm{k}_{1}\left(\mathrm{~min}^{-1}\right)$ and $\mathrm{k}_{2}$ (g/mg.min) are the first-order and second-order absorption equilibrium constant rates, respectively. Also, qe is the amount of material adsorbed per unit mass in equilibrium and $\mathrm{qt}(\mathrm{mg} / \mathrm{g})$ is the amount of capacity of the adsorbed material at time $(\mathrm{t})$. 
Table 5

The kinetics coefficients of MG dye adsorption at different adsorbent doses.

\begin{tabular}{|c|c|c|c|c|c|c|c|c|}
\hline \multirow[t]{3}{*}{ Adsorbent } & \multirow{3}{*}{$\begin{array}{l}\text { dose } \\
(\mathrm{g})\end{array}$} & \multirow[t]{3}{*}{$\left(q_{e}\right)_{\operatorname{Exp}}$} & \multicolumn{3}{|c|}{ Pseudo-first-order } & \multicolumn{3}{|c|}{ Pseudo-second-order } \\
\hline & & & \multicolumn{3}{|c|}{$\log \left(\mathrm{q}_{\mathrm{e}}-\mathrm{q}_{\mathrm{t}}\right)=\log \mathrm{q}_{\mathrm{e}}-\left(\mathrm{k}_{1} / 2.303\right) \cdot \mathrm{t}$} & \multicolumn{3}{|c|}{$\mathrm{t} / \mathrm{q}_{\mathrm{t}}=1 / \mathrm{k}_{2} \cdot \mathrm{q}_{\mathrm{e}}^{2}+\mathrm{t} / \mathrm{q}_{\mathrm{e}}$} \\
\hline & & & $\left(\mathrm{q}_{\mathrm{e}}\right)_{\text {Cal. }}$ & $\mathrm{k}_{1}$ & $\mathrm{R}^{2}$ & $\left(\mathrm{q}_{\mathrm{e}}\right)_{\mathrm{Cal}}$ & $\mathrm{k}_{2}$ & $\mathrm{R}^{2}$ \\
\hline \multirow[t]{4}{*}{$\mathrm{CMC} / \mathrm{GG}$} & 0.05 & 15.22 & 10.36 & 0.009 & 0.9392 & 16.20 & 0.009 & 0.9993 \\
\hline & 0.07 & 12.49 & 8.79 & 0.008 & 0.9636 & 13.44 & 0.009 & 0.9989 \\
\hline & 0.09 & 12.09 & 5.60 & 0.009 & 0.8729 & 12.45 & 0.024 & 0.9995 \\
\hline & 0.1 & 12.80 & 7.61 & 0.015 & 0.9623 & 13.10 & 0.039 & 1 \\
\hline \multirow[t]{4}{*}{$\mathrm{CMC} / \mathrm{GG} / \mathrm{CuO}-3$} & 0.05 & 13.59 & 12.24 & 0.012 & 0.8961 & 14.40 & 0.012 & 0.9987 \\
\hline & 0.07 & 14.85 & 8.39 & 0.014 & 0.9101 & 14.42 & 0.011 & 0.9999 \\
\hline & 0.09 & 16.27 & 6.20 & 0.010 & 0.8404 & 16.52 & 0.035 & 0.9998 \\
\hline & 0.01 & 18.49 & 5.10 & 0.011 & 0.8056 & 18.62 & 0.061 & 1 \\
\hline
\end{tabular}




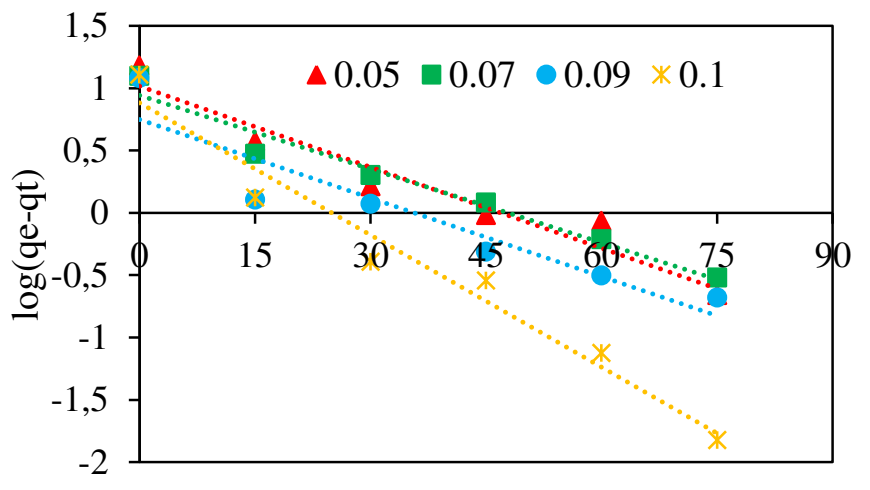

Time (min)

(a)

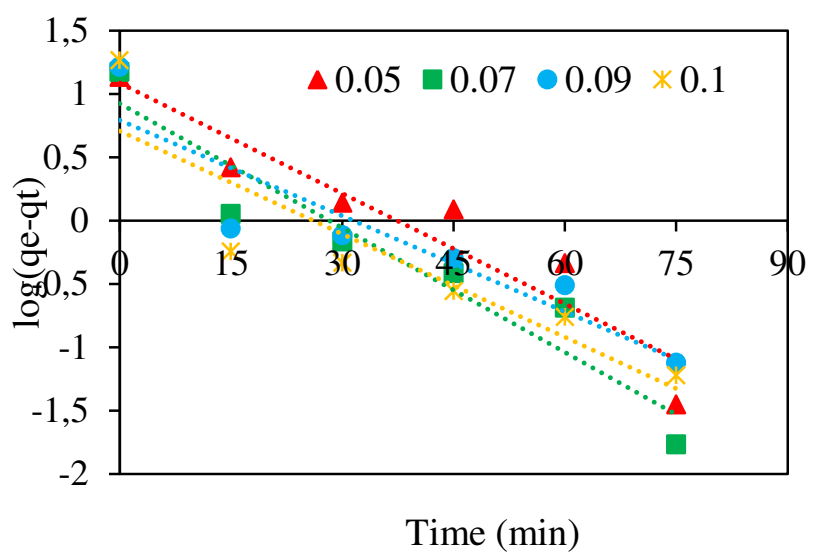

(c)

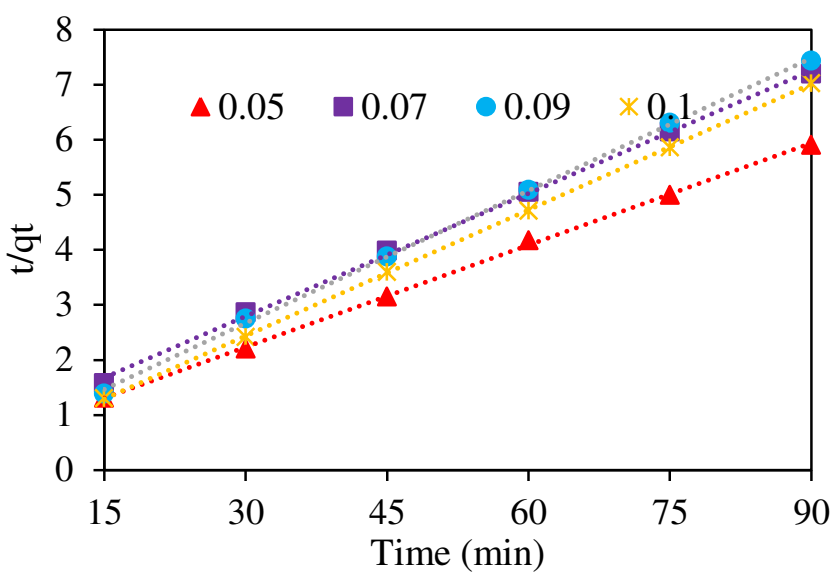

(b)

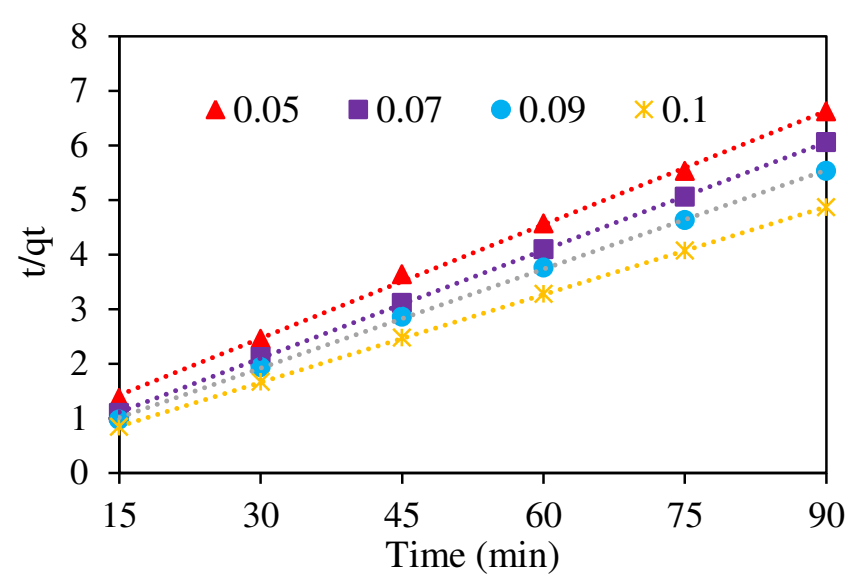

(d)

Fig.12. The first order kinetic (a) $\mathrm{CMC} / \mathrm{GG}$; (b) $\mathrm{CMC} / \mathrm{GG} / \mathrm{CuO}$ and the second order kinetic (c) $\mathrm{CMC} / \mathrm{GG}$; (d) CMC/GG/CuO on dye MG. 


\section{Conclusion}

According to the results of the experiments, it can be said that the biopolymer adsorbent based on copper oxide $(\mathrm{CMC} / \mathrm{GG} / \mathrm{CuO})$ nanoparticles is a good adsorbent for cationic dye bleaching of MG. So that by using the optimal amount of adsorbent $0.1 \mathrm{~g}$ with an initial concentration of dye of $20 \mathrm{mg} / \mathrm{L}$ at a $\mathrm{pH}$ of 6.5 and within $90 \mathrm{~min}$ to achieve the removal efficiency $92.4 \%$ and adsorption capacity $18.6 \mathrm{mg} / \mathrm{g}$. The adsorption kinetics follow a second order with a correlation coefficient $\mathrm{R}^{2}=1$. The isothermal model also follows the Freundlich correlation coefficient $\mathrm{R}^{2}=0.9437$, which indicates the non-uniformity of the adsorption position on the adsorbent surface.

\section{Reference}

[1] N.M. Mahmoodi, M. Oveisi, M. Bakhtiari, B. Hayati, A.A. Shekarchi, A. Bagheri, S. Rahimi, Environmentally friendly ultrasound-assisted synthesis of magnetic zeolitic imidazolate framework - Graphene oxide nanocomposites and pollutant removal from water, J. Mol. Liq. 282 (2019) 115-130. https://doi.org/10.1016/j.molliq.2019.02.139.

[2] A. Bagheri, H. Hoseinzadeh, B. Hayati, N.M. Mahmoodi, E. Mehraeen, Post-synthetic functionalization of the metal-organic framework: Clean synthesis, pollutant removal, and antibacterial activity, Biochem. Pharmacol. $3437 \quad$ (n.d.) 104590. https://doi.org/10.1016/j.jece.2020.104590.

[3] A. Almasian, M.E. Olya, N.M. Mahmoodi, Synthesis of polyacrylonitrile/polyamidoamine composite nanofibers using electrospinning technique and their dye removal capacity, J. Taiwan Inst. Chem. Eng. 49 (2015) 119-128. https://doi.org/10.1016/j.jtice.2014.11.027. 
[4] B. Hayati, N.M. Mahmoodi, A. Maleki, Dendrimer-titania nanocomposite: Synthesis and dye-removal capacity, Res. Chem. Intermed. 41 (2015) 3743-3757. https://doi.org/10.1007/s11164-013-1486-4.

[5] M.A.M. Salleh, D.K. Mahmoud, W.A.W.A. Karim, A. Idris, Cationic and anionic dye adsorption by agricultural solid wastes: A comprehensive review, Desalination. 280 (2011) 1-13. https://doi.org/10.1016/j.desal.2011.07.019.

[6] A.S. Eltaweil, H. Ali Mohamed, E.M. Abd El-Monaem, G.M. El-Subruiti, Mesoporous magnetic biochar composite for enhanced adsorption of malachite green dye: Characterization, adsorption kinetics, thermodynamics and isotherms, Adv. Powder Technol. 31 (2020) 1253-1263. https://doi.org/10.1016/j.apt.2020.01.005.

[7] S. Arellano-Cárdenas, S. López-Cortez, M. Cornejo-Mazón, J.C. Mares-Gutiérrez, Study of malachite green adsorption by organically modified clay using a batch method, Appl. Surf. Sci. 280 (2013) 74-78. https://doi.org/10.1016/j.apsusc.2013.04.097.

[8] N. Buvaneswari, C. Kannan, Plant toxic and non-toxic nature of organic dyes through adsorption mechanism on cellulose surface, J. Hazard. Mater. 189 (2011) 294-300. https://doi.org/10.1016/j.jhazmat.2011.02.036.

[9] M. Arami, N.Y. Limaee, N.M. Mahmoodi, N.S. Tabrizi, Removal of dyes from colored textile wastewater by orange peel adsorbent: Equilibrium and kinetic studies, J. Colloid Interface Sci. 288 (2005) 371-376. https://doi.org/10.1016/j.jcis.2005.03.020.

[10] Z. Yang, H. Peng, W. Wang, T. Liu, Crystallization behavior of poly $(\varepsilon-$ caprolactone)/layered double hydroxide nanocomposites, J. Appl. Polym. Sci. 116 (2010) 2658-2667. https://doi.org/10.1002/app. 
[11] P.R. of C. Key Laboratory of the Ministry of Education for Advanced Catalysis Materials, College of Chemistry and Life Science, Zhejiang Normal University, Jinhua, Zhejiang 321004, Development of a Novel Core-Shell Magnetic Fe3O4@CMC@ZIF-8-.pdf, (n.d.).

[12] N.M. Mahmoodi, M.H. Saffar-Dastgerdi, Clean Laccase immobilized nanobiocatalysts (graphene oxide - zeolite nanocomposites): From production to detailed biocatalytic degradation of organic pollutant, Appl. Catal. B Environ. (2019) 118443. https://doi.org/10.1016/j.apcatb.2019.118443.

[13] N.M. Mahmoodi, M. Taghizadeh, A. Taghizadeh, J. Abdi, B. Hayati, A.A. Shekarchi, Bio-based magnetic metal-organic framework nanocomposite: Ultrasound-assisted synthesis and pollutant (heavy metal and dye) removal from aqueous media, Appl. Surf. Sci. 480 (2019) 288-299. https://doi.org/10.1016/j.apsusc.2019.02.211.

[14] A. Asghar, A. Aziz, A. Raman, W. Mohd, A. Wan, Advanced oxidation processes for insitu production of hydrogen peroxide / hydroxyl radical for textile wastewater treatment : a review, J. Clean. $\quad$ Prod. $87 \quad$ (2015) 826-838. https://doi.org/10.1016/j.jclepro.2014.09.010.

[15] N.M. Mahmoodi, M.H. Saffar-Dastgerdi, Zeolite nanoparticle as a superior adsorbent with high capacity: Synthesis, surface modification and pollutant adsorption ability from $\begin{array}{lllll}\text { wastewater, } & \text { Microchem. } & \text { J. } & 145 & \text { 74-83. }\end{array}$ https://doi.org/10.1016/j.microc.2018.10.018.

[16] M. Hashem, S. Sharaf, M.M. Abd El-Hady, A. Hebeish, Synthesis and characterization of novel carboxymethylcellulose hydrogels and carboxymethylcellulolse-hydrogel-ZnO- 
nanocomposites, $\quad$ Carbohydr. $\quad$ Polym. $\quad 95 \quad$ (2013) 421-427. https://doi.org/10.1016/j.carbpol.2013.03.013.

[17] Q. Kong, X. Wang, T. Lou, Preparation of millimeter-sized chitosan/carboxymethyl cellulose hollow capsule and its dye adsorption properties, Carbohydr. Polym. 244 (2020) 116481. https://doi.org/10.1016/j.carbpol.2020.116481.

[18] V. Kanikireddy, K. Varaprasad, M.S. Rani, P. Venkataswamy, B.J. Mohan Reddy, M. Vithal, Biosynthesis of CMC-Guar gum-Ag0 nanocomposites for inactivation of food pathogenic microbes and its effect on the shelf life of strawberries, Carbohydr. Polym. 236 (2020) 116053. https://doi.org/10.1016/j.carbpol.2020.116053.

[19] G. Xiong, B. Bin Wang, L.X. You, B.Y. Ren, Y.K. He, F. Ding, I. Dragutan, V. Dragutan, Y.G. Sun, Hypervalent silicon-based, anionic porous organic polymers with solid microsphere or hollow nanotube morphologies and exceptional capacity for selective adsorption of cationic dyes, J. Mater. Chem. A. 7 (2019) 393-404. https://doi.org/10.1039/c8ta07109h.

[20] K. Hattori, E. Abe, T. Yoshida, J.A. Cuculo, New solvents for cellulose. II. Ethylenediamine/thiocyanate salt system, Polym. J. $36 \quad$ (2004) 123-130. https://doi.org/10.1295/polymj.36.123.

[21] P. Rachtanapun, Blended films of carboxymethyl cellulose from papaya peel (CMCp) and corn starch, Kasetsart J. - Nat. Sci. 43 (2009) 259-266.

[22] C.J. Tijsen, H.J. Kolk, E.J. Stamhuis, A.A.C.M. Beenackers, An experimental study on the carboxymethylation of granular potato starch in non-aqueous media, Carbohydr. Polym. 45 (2001) 219-226. https://doi.org/10.1016/S0144-8617(00)00243-5. 
[23] R.K. Singh, A.K. Singh, Optimization of reaction conditions for preparing carboxymethyl cellulose from corn cobic agricultural waste, Waste and Biomass Valorization. 4 (2013) 129-137. https://doi.org/10.1007/s12649-012-9123-9.

[24] A. Bono, P.H. Ying, F.Y. Yan, C.L. Muei, R. Sarbatly, D. Krishnaiah, Synthesis and characterization of carboxymethyl cellulose from palm kernel cake, Adv. Nat. Appl. Sci. 3 (2009) 5-11.

[25] Z. Keilany, Book Reviews: Book Reviews, Rev. Soc. Econ. 36 (1978) 228-229. https://doi.org/10.1080/00346767800000037.

[26] Z. Karimzadeh, S. Javanbakht, H. Namazi, Carboxymethylcellulose/MOF-5/Graphene oxide bio-nanocomposite as antibacterial drug nanocarrier agent, BioImpacts. 9 (2019) 513. https://doi.org/10.15171/bi.2019.02.

[27] R. Saxena, S. Sharma, Adsorption and Kinetic Studies on the Removal of Methyl Red from Aqueous Solutions Using Low-cost Adsorbent: Guargum Powder, Int. J. Sci. Eng. Res. 7 (2016) 675-683. http://www.ijser.org.

[28] G. Sharma, S. Sharma, A. Kumar, A.H. Al-Muhtaseb, M. Naushad, A.A. Ghfar, G.T. Mola, F.J. Stadler, Guar gum and its composites as potential materials for diverse applications: A review, Carbohydr. Polym. 199 (2018) 534-545. https://doi.org/10.1016/j.carbpol.2018.07.053.

[29] V. Jain, V. Tammishetti, K. Joshi, D. Kumar, Pradip, B. Rai, Guar gum as a selective flocculant for the beneficiation of alumina rich iron ore slimes: Density functional theory and experimental studies, Miner. Eng. $109 \quad$ (2017) 144-152. https://doi.org/10.1016/j.mineng.2017.03.007. 
[30] N. Abdullah, M.H. Tajuddin, N. Yusof, Carbon-based polymer nanocomposites for dye and pigment removal, Elsevier Inc., 2018. https://doi.org/10.1016/B978-0-12-8135747.00013-7.

[31] N. Thombare, U. Jha, S. Mishra, M.Z. Siddiqui, Guar gum as a promising starting material for diverse applications: A review, Int. J. Biol. Macromol. 88 (2016) 361-372. https://doi.org/10.1016/j.ijbiomac.2016.04.001.

[32] D. Mudgil, S. Barak, B.S. Khatkar, Guar gum: Processing, properties and food applications - A Review, J. Food Sci. Technol. 51 (2014) 409-418. https://doi.org/10.1007/s13197-011-0522-x.

[33] G. Sharma, A. Kumar, S. Sharma, M. Naushad, A.A. Ghfar, A.H. Al-Muhtaseb, T. Ahamad, N. Sharma, F.J. Stadler, Carboxymethyl cellulose structured nano-adsorbent for removal of methyl violet from aqueous solution: isotherm and kinetic analyses, Cellulose. 27 (2020) 3677-3691. https://doi.org/10.1007/s10570-020-02989-y.

[34] Y. Lv, B. Xing, M. Zheng, G. Yi, G. Huang, C. Zhang, R. Yuan, Z. Chen, Y. Cao, Hydrothermal synthesis of ultra-light coal-based graphene oxide aerogel for efficient removal of dyes from aqueous solutions, Nanomaterials. 8 (2018) 1-17. https://doi.org/10.3390/nano8090670.

[35] N.S.V. Capanema, A.A.P. Mansur, H.S. Mansur, A.C. de Jesus, S.M. Carvalho, P. Chagas, L.C. de Oliveira, Eco-friendly and biocompatible cross-linked carboxymethylcellulose hydrogels as adsorbents for the removal of organic dye pollutants for environmental applications, Environ. Technol. (United Kingdom). 39 (2018) 28562872. https://doi.org/10.1080/09593330.2017.1367845. 
[36] P. Pal, A.G. Corpuz, S.W. Hasan, M. Sillanpää, F. Banat, Simultaneous removal of single and mixed cationic/anionic dyes from aqueous solutions using flotation by colloidal gas aphrons, Sep. Purif. Technol. 255 (2021). https://doi.org/10.1016/j.seppur.2020.117684.

[37] A.S. Eltaweil, G.S. Elgarhy, G.M. El-Subruiti, A.M. Omer, Carboxymethyl cellulose/carboxylated graphene oxide composite microbeads for efficient adsorption of cationic methylene blue dye, Int. J. Biol. Macromol. 154 (2020) 307-318. https://doi.org/10.1016/j.ijbiomac.2020.03.122.

[38] M.A. Khan, N. Nayan, Shadiullah, M.K. Ahmad, C.F. Soon, Surface study of cuo nanopetals by advanced nanocharacterization techniques with enhanced optical and $\begin{array}{lllll}\text { catalytic } & \text { properties, } & \text { Nanomaterials. } & 10 & \text { (2020) }\end{array}$ https://doi.org/10.3390/nano10071298.

[39] C. Tamuly, I. Saikia, M. Hazarika, M.R. Das, Reduction of aromatic nitro compounds catalyzed by biogenic $\mathrm{CuO}$ nanoparticles, RSC Adv. 4 (2014) 53229-53236. https://doi.org/10.1039/c4ra10397a.

[40] W. Kong, J. Liu, Nitrogen-decorated, porous carbons derived from waste cow manure as efficient catalysts for the selective capture and conversion of CO 2, RSC Adv. 9 (2019) 4925-4931. https://doi.org/10.1039/c8ra10497b.

[41] M. Vall, J. Hultberg, M. Strømme, O. Cheung, Inorganic carbonate composites as potential high temperature $\mathrm{CO} 2$ sorbents with enhanced cycle stability, RSC Adv. 9 (2019) 20273-20280. https://doi.org/10.1039/c9ra02843a.

[42] S. Thakur, B. Sharma, A. Verma, J. Chaudhary, S. Tamulevicius, V.K. Thakur, Recent approaches in guar gum hydrogel synthesis for water purification, Int. J. Polym. Anal. 
Charact. 23 (2018) 621-632. https://doi.org/10.1080/1023666X.2018.1488661.

[43] H. Hoseinzadeh, B. Hayati, F. Shahmoradi, K. Seifpanahi-shabani, N. Mohammad, Development of room temperature synthesized and functionalized metal-organic framework / graphene oxide composite and pollutant adsorption ability, Mater. Res. Bull. 142 (2021) 111408. https://doi.org/10.1016/j.materresbull.2021.111408.

[44] T.A. Khan, M. Nazir, I. Ali, A. Kumar, Removal of Chromium(VI) from aqueous solution using guar gum-nano zinc oxide biocomposite adsorbent, Arab. J. Chem. 10 (2017) S2388-S2398. https://doi.org/10.1016/j.arabjc.2013.08.019.

[45] L.G.T. dos Reis, N.F. Robaina, W.F. Pacheco, R.J. Cassella, Separation of Malachite Green and Methyl Green cationic dyes from aqueous medium by adsorption on Amberlite XAD-2 and XAD-4 resins using sodium dodecylsulfate as carrier, Chem. Eng. J. 171 (2011) 532-540. https://doi.org/10.1016/j.cej.2011.04.024.

[46] S. Abuzerr, M. Darwish, A.H. Mahvi, Simultaneous removal of cationic methylene blue and anionic reactive red 198 dyes using magnetic activated carbon nanoparticles: Equilibrium, and kinetics analysis, Water Sci. Technol. 2017 (2017) 534-545. https://doi.org/10.2166/wst.2018.145.

[47] A.C. Tella, M.D. Olawale, M. Neuburger, J.A. Obaleye, Synthesis and crystal structure of Cd-based metal-organic framework for removal of methyl-orange from aqueous solution, J. Solid State Chem. 255 (2017) 157-166. https://doi.org/10.1016/j.jssc.2017.07.019.

[48] M. Ghaedi, A. Ansari, M.H. Habibi, A.R. Asghari, Removal of malachite green from aqueous solution by zinc oxide nanoparticle loaded on activated carbon: Kinetics and isotherm study, J. Ind. Eng. Chem. 20 (2014) 17-28. 
https://doi.org/10.1016/j.jiec.2013.04.031.

[49] K. Zare, H. Sadegh, R. Shahryari-Ghoshekandi, B. Maazinejad, V. Ali, I. Tyagi, S. Agarwal, V.K. Gupta, Enhanced removal of toxic Congo red dye using multi walled carbon nanotubes: Kinetic, equilibrium studies and its comparison with other adsorbents, J. Mol. Liq. 212 (2015) 266-271. https://doi.org/10.1016/j.molliq.2015.09.027.

[50] N. Marsiezade, V. Javanbakht, Novel hollow beads of carboxymethyl cellulose/ZSM5/ZIF-8 for dye removal from aqueous solution in batch and continuous fixed bed systems, Int. J. Biol. Macromol. 162 (2020) 1140-1152. https://doi.org/10.1016/j.ijbiomac.2020.06.229.

[51] N.M. Mahmoodi, Nickel ferrite nanoparticle: Synthesis, modification by surfactant and dye removal ability, Water. Air. Soil Pollut. 224 (2013). https://doi.org/10.1007/s11270012-1419-7.

[52] N.M. Mahmoodi, F. Najafi, Synthesis, amine functionalization and dye removal ability of titania/silica nano-hybrid, Microporous Mesoporous Mater. 156 (2012) 153-160. https://doi.org/10.1016/j.micromeso.2012.02.026.

[53] F. Doulati Ardejani, K. Badii, N. Yousefi Limaee, N.M. Mahmoodi, M. Arami, S.Z. Shafaei, A.R. Mirhabibi, Numerical modelling and laboratory studies on the removal of Direct Red 23 and Direct Red 80 dyes from textile effluents using orange peel, a low-cost adsorbent, $\quad$ Dye. $\quad$ Pigment. $73 \quad$ (2007) 178-185. https://doi.org/10.1016/j.dyepig.2005.11.011.

[54] N.M. Mahmoodi, M. Oveisi, A. Taghizadeh, M. Taghizadeh, Synthesis of pearl necklacelike ZIF-8@chitosan/PVA nanofiber with synergistic effect for recycling aqueous dye 
$\begin{array}{lllll}\text { removal, } & \text { Carbohydr. } & \text { Polym. } & 227 & \text { (2020) }\end{array}$ https://doi.org/10.1016/j.carbpol.2019.115364.

[55] M. Oveisi, N.M. Mahmoodi, M.A. Asli, Facile and green synthesis of metal-organic framework/inorganic nanofiber using electrospinning for recyclable visible-light photocatalysis, J. Clean. Prod. $222 \quad$ (2019) 669-684. https://doi.org/10.1016/j.jclepro.2019.03.066.

[56] N.M. Mahmoodi, Dendrimer functionalized nanoarchitecture: Synthesis and binary system dye removal, J. Taiwan Inst. Chem. Eng. 45 (2014) 2008-2020. https://doi.org/10.1016/j.jtice.2013.12.010.

[57] J. Abdi, N.M. Mahmoodi, M. Vossoughi, I. Alemzadeh, Synthesis of magnetic metalorganic framework nanocomposite (ZIF-8@SiO2@MnFe2O4) as a novel adsorbent for selective dye removal from multicomponent systems, Microporous Mesoporous Mater. 273 (2019) 177-188. https://doi.org/10.1016/j.micromeso.2018.06.040. 